\title{
Circumferential pressures on a fixed vertical cylinder in waves
}

\author{
A. G. L. Borthwick and D. M. Herbert
}

\section{Dr Basil W. Wilson, Consulting Oceanographic Engineer, Pasadena, California} The purpose of this discussion is to draw attention to unpublished information (except in the form of project research reports ${ }^{14,15}$ and an incomplete formal report $\left.{ }^{16}\right)$, which bears on the Authors' Paper and results. Specifically, tests were made as long ago as $1955-57$ on a $D=30$ in $(0.75 \mathrm{~m})$ diameter vertical cylindrical test pile, attached to the Magnolia Oil Company's platform 119F in the Gulf of Mexico in $40 \mathrm{ft}(12 \mathrm{~m})$ of water. Fig. 14 shows the location of the test pile and Fig. 15 a schematic diagram of its arrangement for measuring wave force $F$ on the pile at the instantaneous centre of pressure, at level $\bar{s}$ above the sea-bed. The force $F$ had to be derived from the reactions $R$ measured by resistance-wire strain-gauges at the two pinned reaction points 1 and 2 on a smaller section of the cylinder above the test length, as shown.

39. It would be quite impossible in the limited space of this discussion to convey detailed particulars of how the complex combination of a relatively confused sea condition in a tidal current situation with prevailing wind was successfully handled in the analysis of the field results. The Authors are referred to the relevant reports. The data analysed for 24 May, 1955 , were for waves 3-8 ft high, and 5-8 seriod; Table 2 assembles basic parameter information.

40. Measurements of reaction deflexions were made with reference to arbitrary datums in absence of knowledge of true datums. Motion pictures gave water levels at the pile, also referred to arbitrary datum. Necessary corrections to give data referred to true datum were evaluated on a statistical basis by utilizing certain conditional relationships and their moments. In the case of water level, true datum was established as the overall mean of the variations, taken over several wave periods. The problem of correlating motion-picture frames with time, arising from non-uniform motion of the film past the camera shutter, was overcome by comparing corresponding peaks and troughs and mean-level crossings of waves in records of $\eta_{\mathrm{m}}$ and $\eta_{R_{z}}$, respectively water-surface time-profile, measured from motion pictures and derived from vertical reactions $R_{\mathrm{z}}$.

41. Numerical filters were applied to the data for purposes of eliminating high frequency and vibrational fluctuations, and for converting reaction measurements into time-profiles of water-surface elevation $\eta_{\mathrm{m}}$, horizontal water-particle velocities $u$ and accelerations $\dot{u}$ at any level $s$ above the sea-bed. The design of such numerical filters involved approximating a wanted amplitude spectrum, or frequency-response relationship by a Fourier Series, whose numerical coefficients comprised the filter. Filters of 21 coefficients were used in this process. Good

Paper published: Proc. Instn Civ. Engrs, Part 2, 1990, 89, June, 143-162. 


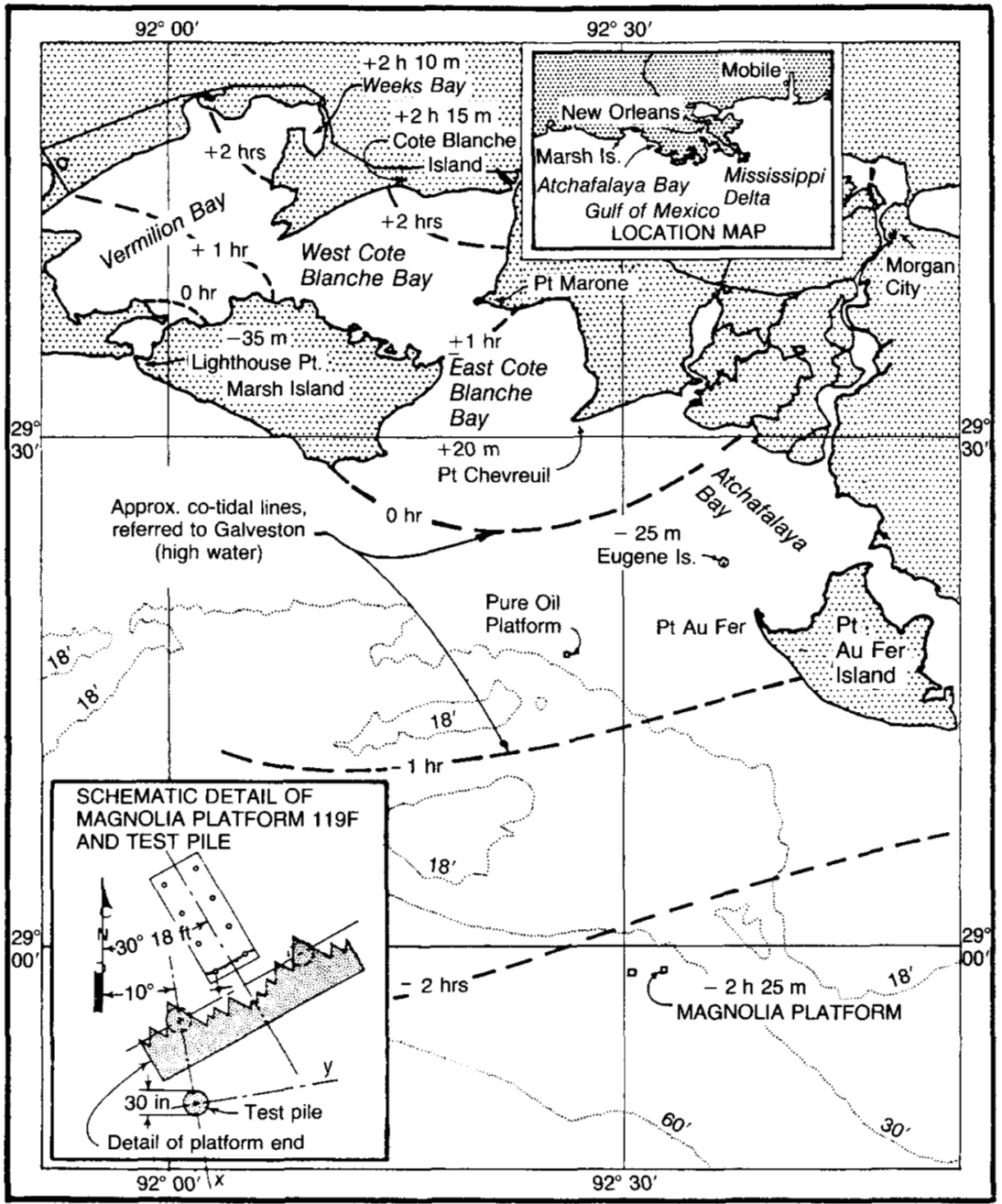

Fig. 14. Location of test pile

correspondence was obtained between vertical-reaction-measured water-surface elevation and that derived from motion pictures.

42. The level of action $\bar{s}$ of total instantaneous horizontal wave force was shown to be a function of water-surface elevation $\eta_{\mathrm{m}}$ and thus was derived from $\eta_{\mathrm{m}}$. Particular values of $\bar{u}$ and $\dot{\bar{u}}$ at the $\bar{s}$ level were obtained by an interpolation process and could be associated directly with a wave force per unit length $\bar{f}$, acting at that level, as given by the total wave force $F$ divided by the immersed length $L$ of the pile. 


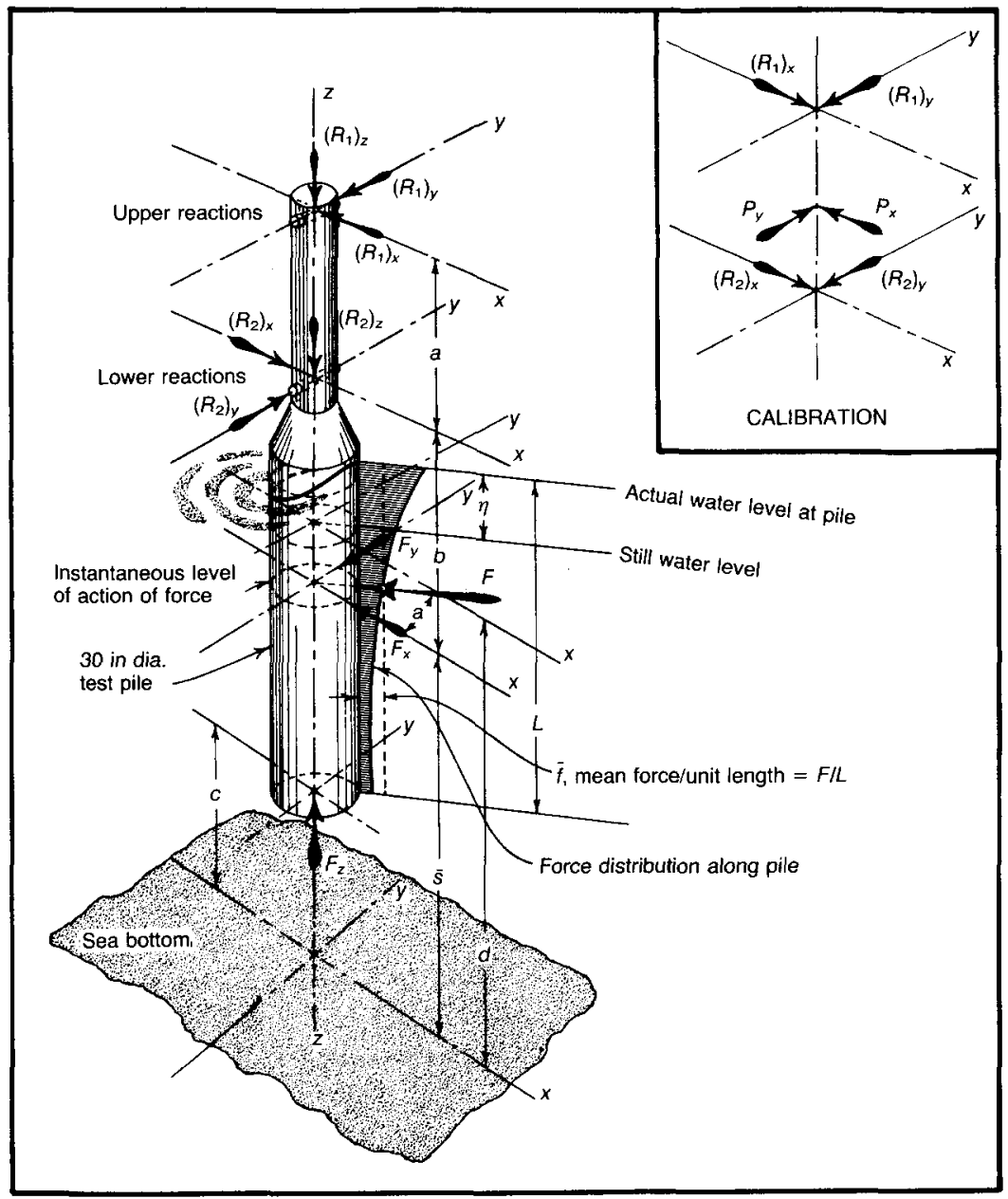

Fig. 15. Schematic diagram of arrangement of pile for measuring wave force $F$

43. Resultants of measured wave forces in the $x$ and $y$ directions showed that these were bearing on the pile from all points of the compass. The obvious conclusion was that a confused sea, comprising two or more wave trains from different directions, existed at the time of the test. An inference was drawn that wave forces were predominantly inertial and therefore simple harmonic. Two simple harmonic systems, acting in different directions and interfering, lead to a 'Lissajous' type of force-field, whose pattern is confined within a circumscribing parallelogram, with sides parallel to the directions of the two systems. Fig. 16 shows the 'Lissajous' figure covering the data of Table 2. From this it was inferred that the sea was the result of locally wind-generated waves from the south-west confusing with swells 


\section{DISCUSSION}

Table 2. Test conditions at Magnolia Oil Company platform 119 F, 24 May, 1955: 30 in dia. test pile

\begin{tabular}{|c|c|c|c|}
\hline Item or dimension & Symbol & Value & Remarks \\
\hline Time of test period & $t$ & 1800-1823, CST & \\
\hline Wind velocity & 一 & 18 knots & Anernometer \\
\hline Wind direction & 一 & $215^{\circ}$ (true North) & reading \\
\hline Wave periods & $T$ & $5-8 \mathrm{~s}$ & Visual \\
\hline Wave height & $H$ & $3-6 \mathrm{ft}(\max 8)$ & observations \\
\hline Wave direction & - & $170^{\circ}$ (true North) & Apparent \\
\hline Tide height & 一 & $-0.5 \mathrm{ft}$ & Derived \\
\hline Rate of fall of tide & - & $0.39 \mathrm{ft} / \mathrm{h}$ & Derived \\
\hline Velocity of ebb tide & $U$ & $0.49 \mathrm{ft} / \mathrm{s}$ & Computed \\
\hline Direction of tidal current & - & $350^{\circ}$ (true north) & Estimated \\
\hline Water depth at test pile & $d$ & $38 \cdot 0 \mathrm{ft}$ & To mean sea level \\
\hline Dia. of test pile & $D$ & $2.5 \mathrm{ft}$ & Outside dia. \\
\hline $\begin{array}{l}\text { Immersed length of test } \\
\text { pile }\end{array}$ & $L$ & $12 \cdot 0 \mathrm{ft}$ & To mean sea level \\
\hline $\begin{array}{l}\text { Clearance between test } \\
\text { pile and sea-bed }\end{array}$ & $c$ & $26 \cdot 0 \mathrm{ft}$ & \\
\hline $\begin{array}{l}\text { Distance between strain- } \\
\text { bar supports }\end{array}$ & $a$ & $16 \cdot 0 \mathrm{ft}$ & \\
\hline Elevation of upper support & $s_{1}$ & $70.5 \mathrm{ft}$ & Above sea-bed \\
\hline Elevation of lower support & $s_{2}$ & $54.5 \mathrm{ft}$ & Above sea-bed \\
\hline
\end{tabular}

from the south-south-east. Because of this, it was necessary to correlate an effective force $F_{\mathrm{e}}$ with the wave characteristics derived from $\eta_{\mathrm{m}}$.

44. Analysis of results proceeded mainly on the basis of two methods for expressing the force relationship

Method I: by Morison's formula ${ }^{17}$

$$
F_{\mathrm{e}} / L=C_{\mathrm{D}} D\left|\bar{u}_{*}\right| \bar{u}_{*}+C_{\mathrm{M}}(\pi / 2) D^{2} \dot{\bar{u}}_{*}
$$

Method II: by dimensional analysis

$$
C_{\mathrm{R}}=\psi\{[R],[I], \ldots\}
$$

where

$$
\text { Euler number } C_{\mathrm{R}}=\left|F_{\mathrm{e}}\right| /\left(L D \bar{u}_{*}^{2}\right)
$$

$$
\begin{aligned}
\text { Reynolds number }[R] & =\left|\bar{u}_{*}\right| D / \nu \\
\text { Iversen number }{ }^{18}[I] & =\left|\dot{\bar{u}}_{*}\right| D / \bar{u}_{*}^{2}
\end{aligned}
$$

where $\psi$ is a function of the dimensionless parameters $[R]$ and $[I]$, and $v$ is the kinematic viscosity of sea water, taken at $10^{-5} \mathrm{ft}^{2} / \mathrm{s}$, and $\bar{u}_{*}=(\bar{u}-U), U$ being the opposing steady velocity of tidal current. Equations (14) and (15) translate to

$$
C_{\mathbf{R}}=D_{\mathrm{D}}+C_{\mathrm{M}}(\pi / 2)[I]
$$

which is equivalent to equation (13).

45. Results of Method I analysis. Using interpolated data and holding $\bar{u}_{*}$ constant at a particular value, variables $\overline{\bar{u}}_{*}$ and $F_{\mathrm{e}}$ could be found for every 


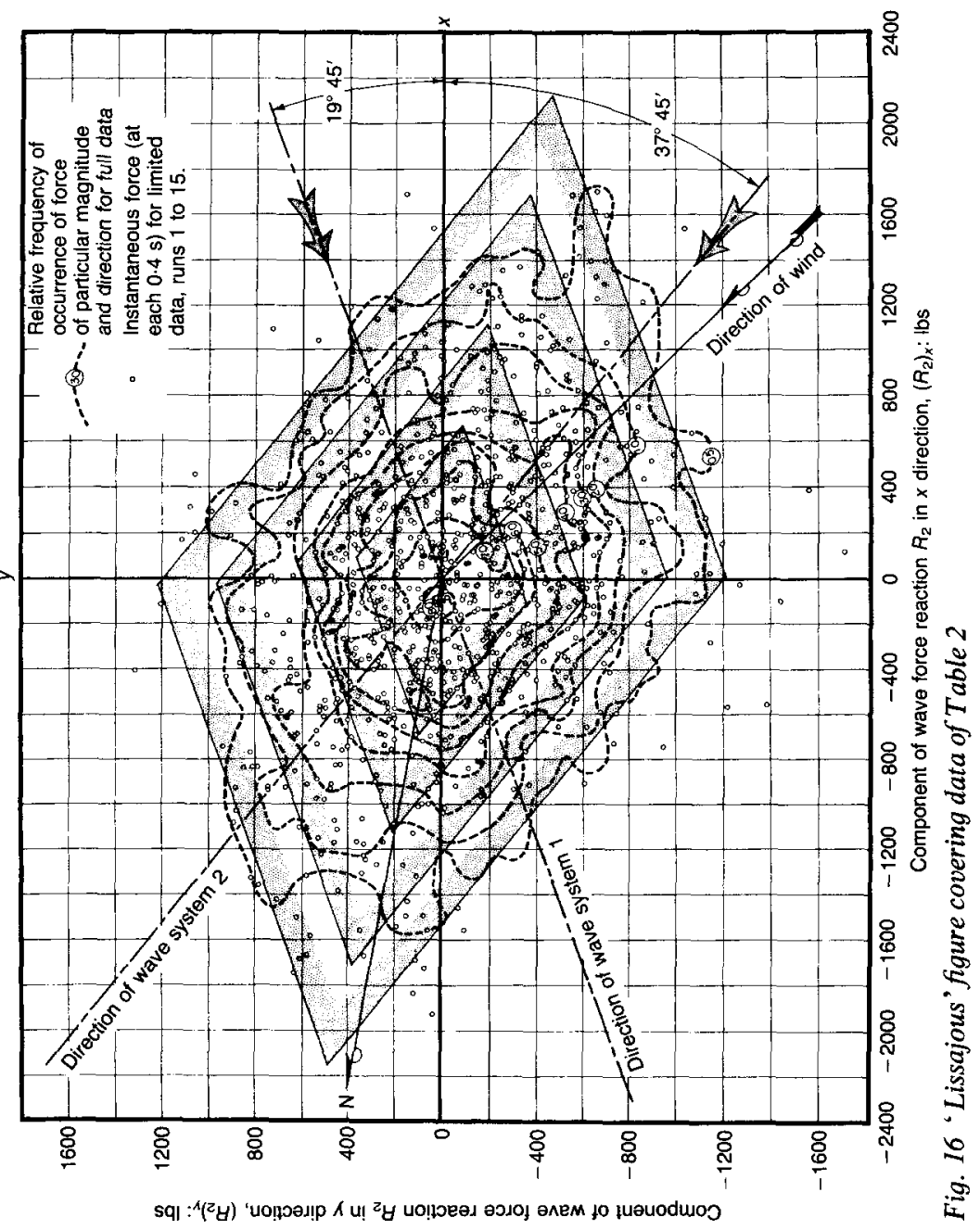




\section{DISCUSSION}

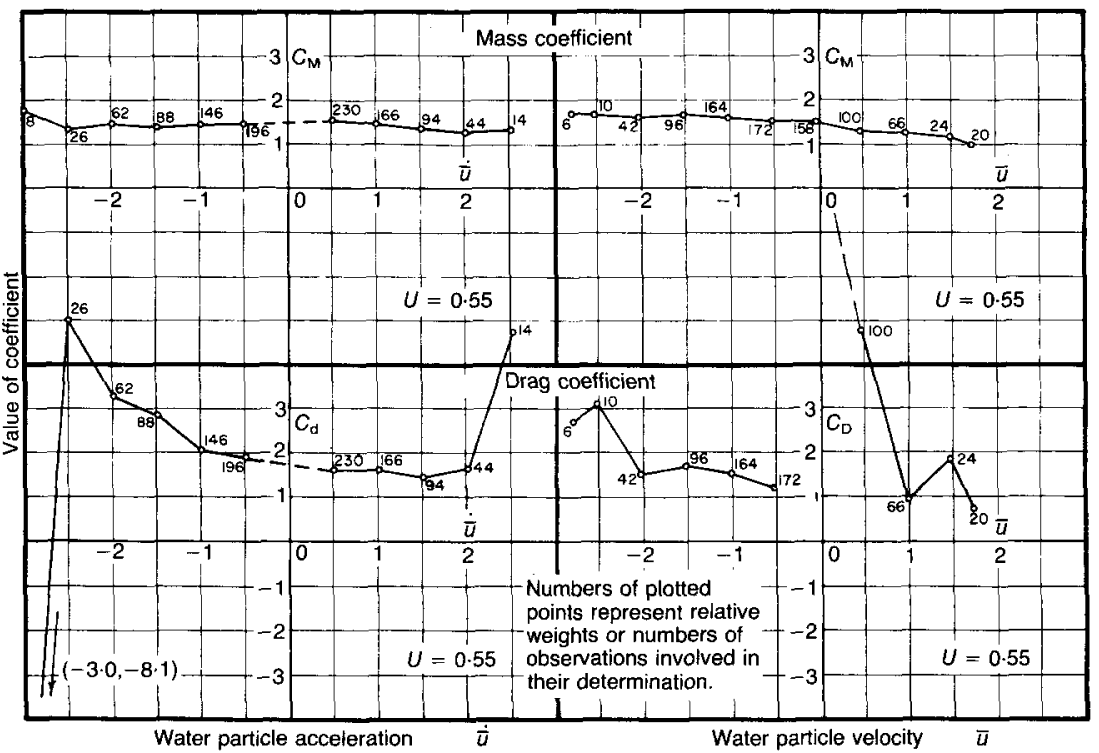

Fig. 17

time-position that $\bar{u}_{*}$ attained the selected value. Similarly, by holding $\dot{\bar{u}}_{*}$ constant at a particular value, $\bar{u}_{*}$ and $F_{\mathrm{e}}$ could be found at times when $\dot{\bar{u}}_{*}$ attained the selected value. By subjecting these data to statistical multiple regression operations, $C_{\mathrm{D}}$ and $C_{\mathrm{M}}$ in equation (13) were evaluated as functions of $\bar{u}$ and $\dot{\bar{u}}$ separately. By trying several possible values of $U$ around the estimated value of $0.49 \mathrm{ft} / \mathrm{s}$, an optimum-fit value of $U=0.55 \mathrm{ft} / \mathrm{s}$ was derived. The mass coefficient $C_{\mathrm{M}}$ emerged as an absolute constant of value 1.45 (Fig. 17). The drag coefficient $C_{\mathrm{D}}$ showed a trend towards values of about 1.6 to 1.7 .

46. Results of Method II analysis. Values of Euler number $C_{\mathbf{R}}$ were collected into groups according to narrow ranges of Reynolds number $[R]$ and then plotted against Iversen number $[I]$. The trend of results favoured a relationship of the form of equation (16), of which the second term (to log-log scaling) yields a straight line of $45^{\circ}$ slope. Using then the value $C_{\mathrm{M}}=1.45$, the data, sorted for specific [R] ranges, were subjected to a least-squares error evaluation of the first term $C_{\mathrm{D}}$. Results are shown in Fig. 18, in which supporting data are plotted collectively. It is to be noted that the seemingly large scatter of points below the regression lines is in part symptomatic of the logarithmic plot. The isolines for the ranges of $[R]$ shown in Fig. 18 are tending to the horizontal at small values of $[I]$, thus defining the appropriate constant $C_{\mathrm{D}}$, as given in the inset table of Fig. 18. At high Reynolds numbers, $C_{\mathrm{D}} \approx 1.0$, but it may be as high as 3.0 at a low $[R] \approx 1.0 \times 10^{5}$.

47. The Keulegan-Carpenter number $K_{\mathrm{c}}$, originally dubbed the 'period parameter' by those authors, is by definition

$$
K_{\mathrm{c}}=u T / D
$$




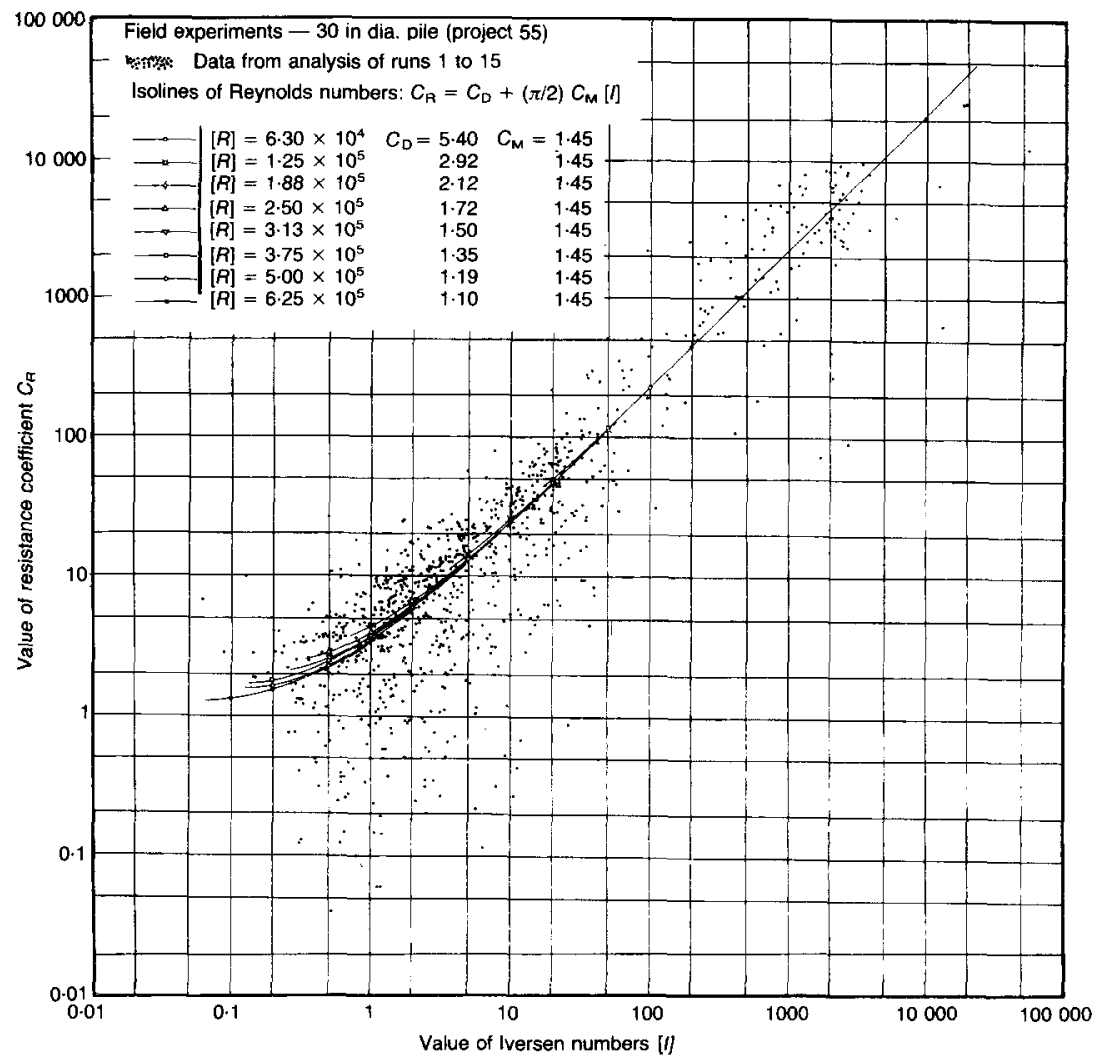

Fig. 18

in which $T$ is the wave period. It is quite readily shown that $K_{\mathrm{c}}$ and $[I]$ are interchangeable through the relationship

$$
K_{\mathrm{c}}=2 \pi /[I]
$$

which thus makes Borthwick and Herbert's Fig. 8 generally similar to Fig. 18, although the latter would tend somewhat to override the plots of Fig. 8. However, Fig. 17 is excellent confirmation of the Authors' Figs 10 and 11.

48. My study of 1955-57 was performed for the Gulf Oil Corporation of Houston, Texas; the wave reaction measurements were initiated by $\operatorname{Dr} C$. $L$. Bretschneider.

\section{Dr Borthwick and Dr Herbert}

It is interesting to see the reasonable agreement between the experimental and the field measurements of inertia coefficient at low Keulegan-Carpenter numbers as shown by comparing Figs 10 and 11 with Dr Wilson's Fig. 18. The inertia coefficient remains nearly constant over the range of Keulegan-Carpenter numbers 


\section{DISCUSSION}

covered in the experimental test programme. This would imply that the inertia coefficient should be relatively insensitive to small changes in the wave conditions at low Keulegan-Carpenter numbers in the sea off the Gulf of Mexico, and may provide a partial explanation for the agreement.

50. At the low values of Keulegan-Carpenter number considered by us, the root-mean-square in-line force coefficient $C_{\mathrm{Frms}}$ is dominated by the contribution from the inertia force component. Equation (16), presented by Dr Wilson, indicates also that the resistance coefficient $C_{\mathrm{R}}$ becomes increasingly weighted by the inertia coefficient, as the Keulegan-Carpenter number reduces and the Iversen number correspondingly increases. Given the agreement between measured inertia coefficients discussed above, it is not surprising that Fig. $8\left(C_{\mathrm{Frms}}\right.$ against local Keulegan-Carpenter number $K_{c}$ ) is essentially similar to Dr Wilson's Fig. 17 $\left(C_{\mathrm{R}}\right.$ against Iversen number $\left.I\right)$.

51. It would be interesting to compare Dr Wilson's unpublished data with that of other large-scale tests, such as provided by Wiegel, Beebe and Moon, ${ }^{19}$ and by Bishop and Shipway. ${ }^{20}$ For example, Wiegel et al. used piles up to $5 \mathrm{ft}$ in diameter in water $50 \mathrm{ft}$ deep off the coast of California in the early 1950s. In general, large-scale tests have yielded a large scatter in drag and inertia coefficients as a result of the sheer complexity of the flow conditions encountered in sea waves. There is continuing research in this area, particularly with regard to the use of statistical methods for analysing data (for example, the work of Davies, Graham and Bearman ${ }^{21}$ ).

\section{References}

14. WILSON B. W. IBM Computer procedures and special methods used in analysis of wave force data-30-inch diameter test pile, Gulf of Mexico. Texas A\&M Research Foundation, College Station, Texas, 1957, June, Technical Report 55-6 (Report to the Gulf Oil Corporation, Houston, Texas).

15. WILSON B. W. Results of analyses of wave force data-confused sea conditions round a 30-inch diameter test pile, Gulf of Mexico. Texas A\&M Research Foundation, College Station, Texas, 1957, July, Technical Report 55-7 (Report to the Gulf Oil Corporation, Houston, Texas).

16. WILSON B. W. Analyses of wave forces on a 30-inch diameter pile under confused sea conditions. US Army Coastal Engineering Research Center, 1965, Oct., Technical Memo. 15 (incomplete).

17. Morison J. R. et al. The force exerted by surface waves on piles. Petrol. Trans. Am. Inst. Min. Metall. Engrs, 1950, 189, 340-370.

18. IVERSEN H. W. and BaLENT R. A correlating modulus for fluid resistance in accelerated flow. J. Appl. Phys., 1951, 22, 324-328.

19. WiEgel R. L. et al. Ocean-wave forces on circular cylindrical piles. J. Hydraul. Div. Am. Soc. Civ. Engrs, 1957, 83, No. HY2, Apr., 1-36.

20. BISHOP J. R. and SHIPWAY J. C. Wave force coefficients from the second Christchurch Bay Tower. NMI Report R178, 1984.

21. Davies M. S. J. et al. In-line forces on fixed cylinders in regular and random waves. Advances in underwater technology, ocean science and offshore engineering. 26: Environmental forces on offshore structures and their prediction. Society for Underwater Technology, 1990, 113-136. 